\title{
SOBRE ESCRITURA FEMENINA EN REVISTA ALPHA: EL APORTE INTELECTUAL ARGENTINO
}

\author{
Nelson Vergara Muñoz* \\ Viviana Troncoso Salazar**
}

Esta nota es una aproximación al aporte femenino en la constitución y consolidación de Revista Alpha. Dilucidar sus intereses y preocupaciones contribuye al objetivo de ser una instancia no ajena a la manifestación de temas humanísticos, pues ha logrado entregar una perspectiva de género, cuando la historia nos ofrece todavía, mayoritariamente, voces masculinas como poseedoras y constructoras del conocimiento, por lo que artículos como a los que haremos referencia son un desafío a esa tradición. ${ }^{1}$

En los estudios crítico-literarios femeninos de Alpha se cruzan la filosofía, los estudios culturales, las materias de género, de diferenciación y construcción identitaria, entre otros. También se desarrollan artículos referentes a lingüística y educación, en menor cantidad, comúnmente resultado de investigaciones. Cuantitativamente, hablamos que de un total de cuatrocientas ochenta y cuatro colaboraciones - desde la edición $\mathrm{N}^{\circ} 1$ a la $\mathrm{N}^{\mathrm{o}} 29$ - ciento cuarenta y cuatro son de autoría individual y/o compartida de mujeres, las que cubren todas las posibilidades de composición: artículos, reseñas, notas, documentos y entrevistas. Asimismo, podemos consignar que los países de origen de estas mujeres son también diversos, primando las publicaciones latinoamericanas sobre las europeas o norteamericanas.

La presencia de intelectuales femeninas se inicia en el $\mathrm{N}^{\circ} 1$ (1985) que inaugura Minerva Rosas con una aportación sobre enseñanza-aprendizaje de un idioma extranjero. Los primeros cuatro números tienen en común el desarrollo de temáticas de lingüística. De aquí en adelante Álvarez-Santullano contribuirá siempre con estudios sobre lengua Huilliche que son el resultado de sus investigaciones en este campo; con Lilian Rodríguez entramos al género dramático. Su artículo "Sistemas semióticos claves para una lectura de El tintero de Carlos Muñiz" ( $\left.\mathrm{N}^{\circ} 2\right)$ afirma como sistemas semióticos esenciales para comprender una obra dramática la escenografía, el vestuario, la iluminación y la música, pues anuncian los momentos cruciales de una obra. Por su parte, Silvia Susana Díaz inicia los estudios literarios del género narrativo con "El negro en la literatura de cordel de Salvador-Bahía" ( $\left.\mathrm{N}^{\circ} 4\right)$, una especificación del rol del hombre negro en los textos de cordel, y en los relatos folclóricos y populares del nordeste de Brasil.

\footnotetext{
${ }^{1}$ Como no se realizará un estudio acabado sino una panorámica de la escritura femenina, nos referiremos a números y textos ícono o cuyos tópicos parecen de mayor interés y novedad.
} 
En temáticas referentes al cine y los estudios literarios encontramos tres artículos sobre cine y literatura: "Los lenguajes de El nombre de la rosa" de Inés de Allende ( $\left.\mathrm{N}^{\circ} 6\right)$; "Performance y nuevas tecnologías" de Josefina Alcázar" ( $\left.{ }^{\circ} 14\right)$; "El microtráfico y lo femenino en el cine colombiano internacional: "Rosario Tijeras y María llena eres de gracia" de Stacey Alba Skar ( $\left.{ }^{\circ} 25\right)$. El primero es una explicación acerca de la transformación de un texto narrativo en guión literario o cinematográfico, analizado a partir de la obra de Umberto Eco. El segundo se refiere a la adaptación del arte a las nuevas tecnologías y al desarrollo de una cultura de la imagen. En el tercero, su autora "argumenta que los directores internacionales llevan sus producciones artísticas al mercado del consumo global con mensajes que reafirman las jerarquías nacionales e internacionales de reproducción masculina". (115), Cita muy decidora como puede verse.

Sobre educación hay seis publicaciones. Cinco a modo de artículos $\left(\mathrm{N}^{\circ} 1 ; \mathrm{N}^{\circ} 7 ; \mathrm{N}^{\circ} 18 ; \mathrm{N}^{\circ} 19 ; \mathrm{N}^{\circ} 25\right)$ y uno como nota $\left(\mathrm{N}^{\circ} 6\right)$. Los aportes chilenos a esta temática poseen la particularidad de ser los únicos para los cuales la educación formal es un tópico de interés, cuyo precedente es el ya mencionado artículo de Minerva Rosas en la edición $\mathrm{N}^{\circ} 1$.

Con el advenimiento de los movimientos feministas, las investigaciones ingresan al ámbito de los estudios culturales. Del análisis estructural se pasa a la crítica al orden y a la herencia masculina en las obras literarias que se estudian en Alpha. En el №15, Lucía Guerra pone de manifiesto su perspectiva sobre el tratamiento y consideración femenina en la narrativa. En "Las oscilaciones de la casa en la narrativa de la mujer latinoamericana" esta investigadora chilena examina la casa como un espacio de anulación de la mujer, considerando que ella ha sido relegada para ser, únicamente, madre y esposa, restringida por el orden patriarcal. Con su texto inicia una larga discusión en la que propone el estudio de la narrativa y de los eventos sociales desde una óptica de género y, sobre todo, como género relegado.

Hasta el $\mathrm{N}^{\circ} 19$, hay cinco estudios de obras literarias de autoría femenina: Eugenia Toledo, "Isabel Allende: la fórmula de una escritora" $\left(N^{\circ} 9\right)$; Corina Rosenfeld, "Una historia de vida: El diario de Santa Teresa de Los Andes" (N¹0); Eugenia Toledo y Kathleen Machugh, "Tejer y destejer" en Cecilia Vicuña ( $\left.{ }^{\circ} 11\right)$, y Estela Valverde, "Teresa Porzecanski: La historia comienza en los ghettos" ( $\left.\mathrm{N}^{\circ} 12\right)$. Con estos trabajos se observa, ya, una tendencia hacia el análisis de narrativa femenina, pero es en el $\mathrm{N}^{\circ} 15$ donde la cuestión de género o masculino/femenino se plantea como posibilidad de discusión. En adelante, vemos que quince artículos presentan propuestas abiertamente feministas que ponen en tela de juicio el patriarcado tradicional. En esta área, Lucía Guerra y Tatiana Calderón contrastan respecto al lugar de la mujer en la sociedad y el modo de relación de ella con el entorno a partir de la casa. Guerra la presenta como espacio que restringe y al que queda 
relegada; Calderón afirma que "La casa, figura metonímica, sugiere otra cartografía significante de la ciudad y plantea la a-territorialidad de la mujer en el mundo posmoderno" (43), pues la casa ha dejado de ser espacio íntimo y se convierte en un recinto público.

En orden descendente, los aportes en relación al origen de las autoras se organizan como sigue: Chile (56), Argentina (33), Estados Unidos (26), Venezuela (10), España (8), México (7) y Francia (7). La suma de estas cifras da un total de ciento cincuenta y cinco nombres femeninos que aparecen publicados por la Revista. A esa suma, debemos restar 11 publicaciones que corresponden a autorías compartidas, lo que da un total de 144 títulos aportados por mujeres.

La mayor cantidad de aportes femeninos a Alpha, como se observa, son de origen chileno, sin embargo, nos interesan las argentinas ya que dentro de las latinoamericanas su aporte es el mayor. Además, estas intelectuales se presentan como estudiosas de la literatura nacional y regional, y respecto a este último, destaca la referencia al espacio patagónico como escenario de obras literarias: Nilda Flawiá, Silvia Casini y Silvia Ruth Bittar ponen de relieve en esta literatura cuestiones de carácter identitario y sus representaciones en la ficción literaria. Particularmente, nos interesan las dos últimas porque manifiestan entre sí unidad temática y un sentimiento localista presente en las producciones, posiblemente, porque ambas aportan sus análisis desde la Universidad Nacional de la Patagonia San Juan Bosco. Es decir, hay con ellas una proximidad temática-regional que nos resulta muy significativa.

La presencia de intelectuales argentinas data de 1988 (Alpha $\mathrm{N}^{\circ} 4$ ), con el estudio ya mencionado de Silvia Susana Díaz, que inaugura el estudio de obras narrativas. Hasta el $\mathrm{N}^{\circ} 8$ se encuentran cinco publicaciones donde aparecen, entre otras, interpretaciones de obras de José Donoso y de Francisco Quevedo. Estos aportes se interrumpen hasta el $\mathrm{N}^{\mathrm{o}} 16$ con colaboraciones de Mónica Bueno (quien cuenta con dos publicaciones). El artículo "Oliverio Girondo y Raúl González Tuñón: dos mundos de la vanguardia" (11-36) propone que estos dos autores postulan "poéticas que tienen un enfoque opuesto de la poesía y el arte, pero que ambos están unidos por ese empecinamiento evidente de ser poetas vanguardistas, más allá de todo determinismo histórico..." (12). En este mismo

número nos encontramos con un artículo de corte completamente distinto: "El dilema de la responsabilidad histórica" de María Esperanza Casullo, quien alude a que el sujeto por poseer voluntad debiera reflexionar ante los impulsos de ésta para evitar cometer un error de carácter criminal, una reflexión que se lleva a cabo a partir de la obra de Merleau-Ponty y Arendt.

En el $\mathrm{N}^{\circ} 17$ de Alpha ingresa una de las temáticas en la que nos interesa hacer hincapié: la identidad. En evidencia queda con el título "La construcción de representaciones identitarias en textos del siglo XIX": "Peregrinación de luz del día" de J. B. Alberdi y "Argirópolis" de D. F. Sarmiento" (11-26), de Nilda 
Flawiá quien, en adelante, continuará con aportes de este tipo. N. Flawiá afirma que estos autores sienten responsabilidad sobre la cultura y desarrollan en su obra esta temática como lectura de la realidad según sus propias experiencias de vida. A este artículo lo sigue una reseña hecha por Silvia Ruth Bittar sobre "Los bárbaros de la Patagonia" (289-293), de Silvia Casini, indicándose que la ensayista "observa que los viajeros del siglo XIX reeditan, con el mismo criterio de aquellos otros del siglo XVI, la carga de prejuicios que trae aparejado el desconocimiento de un espacio nuevo, que presenta otras pautas imposibles de decodificar por quienes sólo se atienen a los parámetros provistos por la cultura occidental" (289). Así, la autora analiza las crónicas de Antonio Pigafetta, el testimonio de Charles Darwin, de George Musters y de Lucas Bridges, quienes "suman imágenes de la ambigüedad general de un discurso que devela como salvaje al nativo patagónico" (ídem).

La participación femenina argentina en este número finaliza con Silvia Casini, que de los cinco textos que ofrece hasta ahora $\left(\mathrm{N}^{\circ} 29\right)$ es el primero que se distancia del estudio del espacio patagónico. La reseña "Gladis Ilarregui (ed.) Femenino Plural. La locura, la enfermedad, el cuerpo en las escritoras hispanoamericanas. Escritos contra el margen" (293-298) remite a los once ensayos divididos en Época Colonial y Época Contemporánea que hablan de la condición femenina y de su tratamiento en un mundo dominado por los hombres (en textos literarios de mujeres) e indagan en lo que a Casini le llama, particularmente, la atención como es "la necesidad de bucear...en las zonas más profundas y dolorosas del discurso femenino" (293) que caracterizan los textos de escritoras hispanoamericanas. Casini destaca en su reseña la construcción de "categorías que constituyen lo que debe aceptarse como la más femenina representación del mundo, ubicando a la mujer en un espacio claustrofóbico y marginal" (ídem). Es manifiesto, entonces, que esta reseña pertenece a los textos que se plantean como estudios de género al borde del feminismo que aparecen en Alpha.

En el Nº18, Bittar y Casini continúan presentes, reingresando, además, Nilda Flawiá. De ellas, Bittar y Flawiá realizan estudios de literatura nacional: la primera con su artículo "El espacio patagónico como ámbito de lo posible en La tierra leve de Elpidio Isla" (135-156) en el cual analiza el motivo literario del viaje como posibilidad de búsqueda y encuentro de la verdad de sí mismo. Según las autoras, Isla "pone en evidencia la manera en que la Patagonia — región de la periferia - es un ámbito que posibilita, desde la dualidad vidamuerte/cuerpo-espíritu, que se plantean como aspectos sustanciales respecto de la necesidad humana por descubrir la verdad última: el conocimiento de sí mismo". Por su parte, muy en relación con la temática del artículo anterior, en "La literatura patagónica a la luz del discurso postcolonial" (285-296), Casini estudia la existencia de la literatura en y sobre la Patagonia en el discurso 
postcolonial, análisis que continúa la idea propuesta en su obra Los Bárbaros de la Patagonia reseñada por Bittar en la edición anterior, conforme a la cual, el viajero europeo frente al nativo patagón se instala como poseedor de una cultura enaltecida por la cual no se reconoce el bagaje del otro. Finalmente, Nilda Flawiá con la nota "Tres novelas argentinas en las últimas décadas del siglo XX" (273-284) explica que la literatura del 70 narra esas otras verdades (situación política del país) desde la ficción y que a partir de ella "la recepción leyó en la misma superficie textual arte y política" (274), utilizando para esto "Alabastro, alfombras de Bokhara" y "La muerte como efecto secundario" de Ana María Shua; además de "En tiempos de Laura Osorio" de Cristina Bajo.

En Alpha $\mathrm{N}^{\circ} 19$, Silvia Casini entrega su segundo texto con tema de género. Se trata del estudio "Género sexual y subversión en De noches vienes de Elena Poniatowska" (123-141), selección de dieciséis cuentos, en el cual apunta que los personajes femeninos "tratan de subvertir el orden impuesto por el sistema patriarcal dominante" (123), al tiempo que manifiesta la intención de Poniatowska de denunciar situaciones de marginalidad en el medio mexicano y la motivación a la lucha por un sistema justo en la década del 70' época de crisis política en Latinoamérica como revelaba, también, el artículo de Flawiá en el número anterior. Luego, a modo de nota, Nilda Flawiá con "Argentina: Literatura, búsqueda y cuestionamiento social en dos autoras de fines del siglo XX" (305-316), destaca la incursión en Angélica Gorodischer en el género policial y fantástico, narrativa que con la ruptura de lo canónico y el uso del humor evidencia una ácida crítica social. En Silvia Plaguer, Flawiá recalca que, también, "importan las rupturas pero dentro del género de lo sentimental, de lo erótico y de una narración con tinte autobiográfico" (307). Añade, Flawiá, que en ambas hay una preocupación por aspectos identitarios como roles de la cultura que establecen relaciones cambiantes y enclavadas en los otros discursos y se alejan de las formas creativas tradicionales.

En el $\mathrm{N}^{\circ} 20$, Silvia Casini retoma la idea de la región patagónica, titulando "Luis Sepúlveda: Un viaje Express al corazón de la Patagonia" (103120) a un análisis de Patagonia Express de este escritor chileno, en el que se apunta a las representaciones que se hacen para "re-vitalizar una matriz legendaria y textual ya existente sobre la Patagonia" (103) tal como se revelan en los relatos de viaje del escritor. Casini continúa con este tema en Alpha $\mathrm{N}^{\circ} 23$. Así es como en su artículo "Ficciones de la Patagonia: La invención del sur en la novela de Tempo Giardinelli" (101-116), que tiene como trama el viaje que realiza el protagonista para conocer la Patagonia y terminar la escritura de una novela - creyendo que esta zona le daría lo necesario para finalizar su obra literaria- Casini subraya que hay apego al texto fundador de la re-construcción del espacio patagónico hecho por viajeros del siglo XIX, 
como Darwin, Humboldt, Chatwin, o como Sepúlveda y el mismo Giardinelli en el siglo XX y, de esta forma, en la obra de este último se continúa con la idea de que la Patagonia es un espacio desolado, inmenso y misterioso, también, en la consideración del protagonista. Y apunta, además, que Giardinelli utiliza lo maravilloso e infernal de la Patagonia para señalar la región como un territorio de grandes aventuras.

Hacemos notar que, para no alejarnos de la continuidad temática de nuestro interés, hasta aquí fue omitida la participación de Luciana Andrea Mellado, quien a partir del $\mathrm{N}^{\circ} 22$ ofrece cinco publicaciones (hasta el $\mathrm{N}^{\circ} 26$, julio de 2008) relativas a estudios literarios sobre la obra de José Rodó; Benito Pérez Galdós, Jesús Díaz y Machado de Assis. En un quinto artículo "Aproximaciones a la idea de nación: Convergencias y ambivalencias de una comunidad imaginada" (N²6:29-46) los apartados "La nación: Imaginación y Narración"; "La nación y el tiempo"; "La nación y el Estado", y "Nosotros y los otros en la nación" confluyen en un esbozo de "un soporte teórico básico para pensar posibles vínculos entre nación y narración, particularmente, considerando la importancia que esto tiene para la investigación de las literaturas nacionales" (29).

En suma, la escritura femenina argentina en Revista Alpha nos motivó no sólo por la mayor cantidad de trabajos latinoamericanos sino, además, porque comparten entre sí preocupaciones e intereses que significan sus producciones. Junto a ello destacamos un nacionalismo seguro y sincero que queda demostrado en el estudio de obras literarias de sus coterráneos como, también, la referencia a otros temas que involucran a su país. Así se manifiesta en la correlación que podemos establecer entre Silvia Casini y Luciana Andrea Mellado: la primera interesada en cuestiones locales, la segunda en las visiones de nación.

Y lo que acaso más nos importa: que la importante lista de crítica femenina manifiesta una sensibilidad que se abre a nuevas interpretaciones, sentidos y perspectivas frente a los registros masculinos y revela la creciente aparición de mujeres en la construcción y diseminación del conocimiento del que históricamente han estado alejadas y/o silenciadas en la historia de nuestras culturas.

Universidad de Los Lagos* Departamento de Humanidades y Arte Avda. Alcalde Fuchslocher 1305, Osorno (Chile) nvergara@ulagos.cl

Universidad de Los Lagos** Departamento de Humanidades y Arte (e) Pedagogía en Lengua Castellana y Comunicaciones Avda. Alcalde Fuchslocher 1305, Osorno (Chile) 